\title{
Controlled trial of long term oral potassium supplements in patients with mild hypertension
}

\author{
ALFONSO SIANI, PASQUALE STRAZZULLO, LITTERIO RUSSO, SERGIO GUGLIELMI, \\ LICIA IACOVIELLO, LIBERATO ALDO FERRARA, MARIO MANCINI
}

\begin{abstract}
A 15 week randomised double blind placebo controlled trial of oral potassium supplements (48 mmol daily) was conducted in 37 patients who had mildly increased blood pressure and a normal dietary intake of sodium. After a two month run in and a one week baseline period the patients were randomly assigned to receive either potassium supplements $(n=18)$ or placebo $(n=19)$. By the third week of treatment blood pressure in the actively treated group had decreased significantly compared with that in the placebo group, though the decrease reached its maximum after 15 weeks. Urinary potassium excretion increased significantly in the group who received potassium supplements, but no significant changes were found in plasma sodium and potassium concentrations or in urinary sodium excretion.

In a subgroup of 13 patients who underwent a further nine weeks of treatment with oral potassium supplements at half of the previous dose (24 mmol daily) their blood pressure, at the end of this second study period, was still significantly lower compared with their baseline value but not with that of the placebo group.

These results show that moderate oral potassium supplements are associated with a long term reduction in blood pressure in patients who have mild hypertension.
\end{abstract}

\section{Introduction}

Epidemiological investigations have suggested an inverse association between a habitual dietary intake of potassium and blood

\footnotetext{
Institute of Internal Medicine and Metabolic Disease, Second Medical School, University of Naples, Naples, Italy

ALFONSO SIANI, MD, research fellow

PASQUALE STRAZZULLO, MD, assistant professor of medicine

LITTERIO RUSSO, MD, research fellow

SERGIO GUGLIELMI, MD, research fellow

LICIA IACOVIELLO, MD, research fellow

LIBERATO ALDO FERRARA, MD, assistant professor of medicine

MARIO MANCINI, MD, professor of medicine and head of department

Correspondence to: Dr P Strazzullo, Istituto di Medicina Interna e Malattie Dismetaboliche, Clinica Medica, 2a Facoltà di Medicina, Università di Napoli, Via S Pansini 5, 80131-Napoli, Italy.
}

pressure..$^{1-3}$ The results of several animal studies have also supported the hypothesis of an antihypertensive effect of a high intake of potassium. ${ }^{49}$ On the other hand, there have been only a few adequately controlled trials of oral potassium supplements in man, and these trials have given conflicting results. ${ }^{10-17}$ Though several short term studies have suggested that an oral potassium supplement of $60-175 \mathrm{mmol}$ daily lowers blood pressure to some extent in a significant proportion of hypertensive patients, the long term effectiveness of an increased oral intake of potassium has still not been determined.

To answer this question we carried out a 15 week controlled trial of moderate ( $48 \mathrm{mmol}$ daily) oral potassium supplements in patients who had mild hypertension.

\section{Patient and methods}

Thirty seven patients who had been referred to the hypertension clinic (mean (SD) age 45 (2), range 21-61) participated in the study with their informed consent. The possibility of the presence of secondary hypertension as well as any associated illness or severe complication of the hypertensive disease was excluded after complete routine clinical investigation.

All patients had a systolic blood pressure greater than $160 \mathrm{~mm} \mathrm{Hg}$ or a diastolic blood pressure greater than $90 \mathrm{~mm} \mathrm{Hg}$, or both, during repeated visits to the clinic during a run in phase of two months: their mean (SEM) blood pressure during this period was 149 (2)/95 (1) $\mathrm{mm} \mathrm{Hg}$ supine and 147 (3)/99 (2) $\mathrm{mm} \mathrm{Hg}$ standing. None of the patients had recently taken diuretics or other drugs known to affect potassium metabolism, and none had a plasma potassium concentration of less than $3.5 \mathrm{mmol} / \mathrm{l}$.

The study took the form of a randomised double blind placebo controlled trial. The two month run in was followed by a baseline period of one week, at the end of which the patients were randomly allocated to receive either potassium supplements $(n=18)$ or placebo $(n=19)$ for 15 weeks. Oral potassium supplements comprised $48 \mathrm{mmol}$ potassium daily (two LentoKalium capsules (Boehringer Biochemia Robin, Italy) three times daily). Identical placebo capsules were given to the patients in the control group. The two treatments were prepackaged in identical containers so that both the patients and the medical staff were unaware of the type of treatment being given. Patients were asked to avoid changes in their diet. Their compliance with the treatment was assessed at each visit by questioning and counting the pills.

At the end of the 15 weeks two subgroups of patients, 13 receiving potassium and 10 receiving placebo, agreed to undergo a further nine weeks of treatment with one Lento-Kalium capsule three times daily $(24 \mathrm{mmol}$ potassium daily) or one placebo capsule three times daily, respectively. 
The patients' blood pressures and heart rates were measured twice, one week apart, during the baseline period and every three weeks during each treatment period by a single observer, who did not know which treatment each patient was receiving, using a Hawksley random zero sphygmomanometer. ${ }^{18}$ After the patient had been resting quietly for 30 minutes in the supine position the systolic and diastolic (phase V Korotkoff sounds) blood pressures and the pulse rate were measured three times two minutes apart from each other; the same measurements were repeated after the patient had been standing upright for two minutes. The average of each measurement for all the patients in each position was used in the analysis.

All patients provided two separate 24 hour urine collections during the baseline period and again at the end of the 15 week treatment period so that their 24 hour sodium, potassium, and creatinine excretion could be determined. At the same time a venous blood sample was obtained in the morning after a 12 hour fast to measure serum sodium, potassium, and creatinine concentrations. Serum and urinary electrolyte concentrations

TABLE I-Baseline characteristics of patients (values are means (SEM))

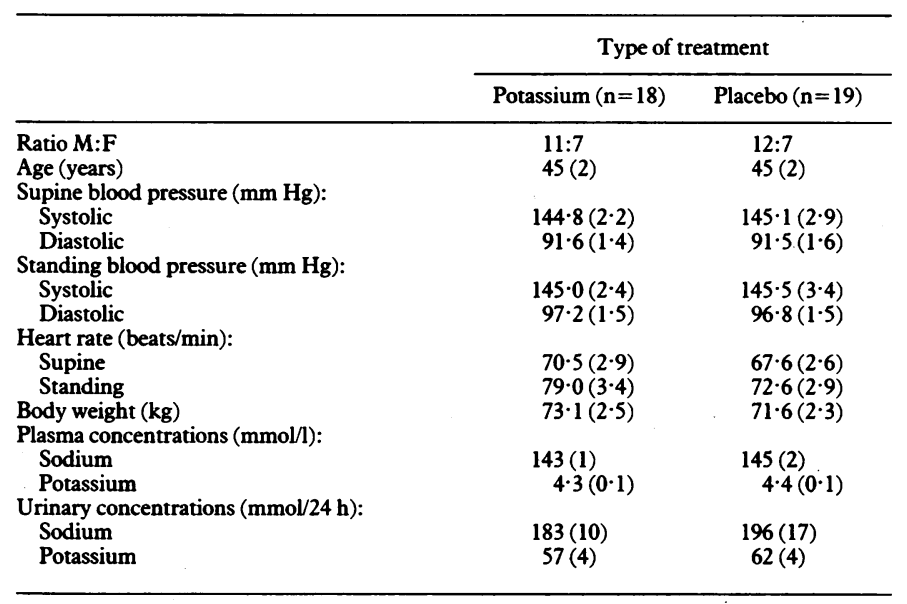

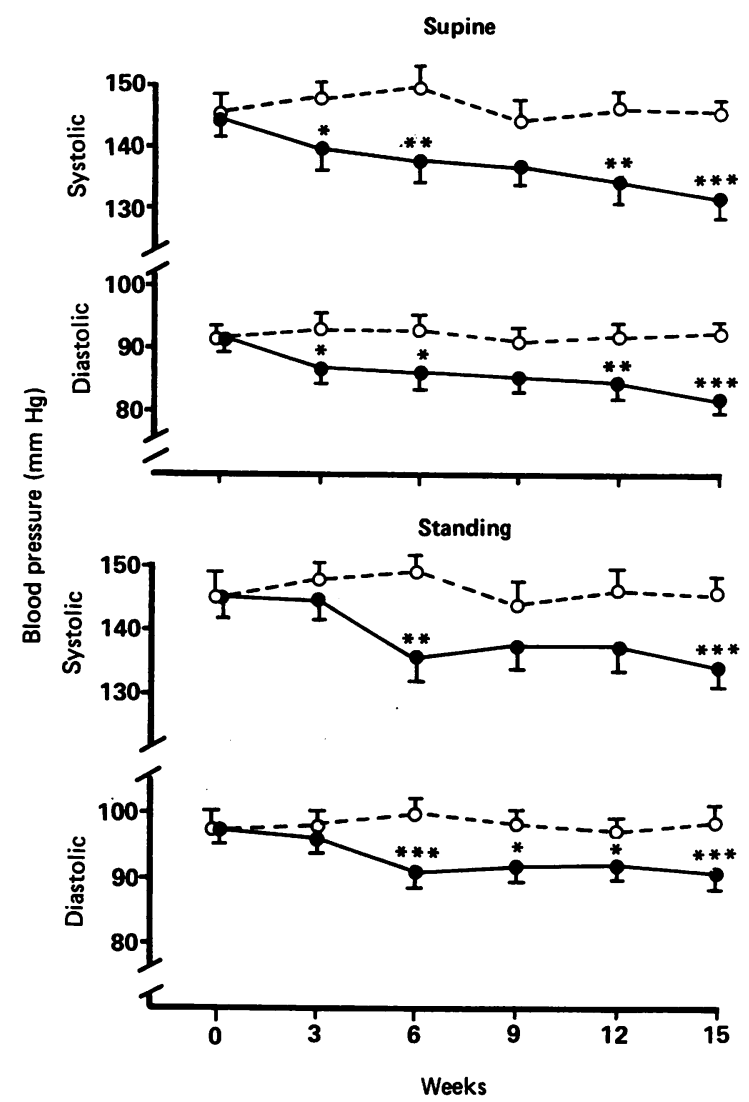

FIG 1-Average supine (above) and standing (below) blood pressures of 18 hypertensive patients receiving oral potassium supplement of $48 \mathrm{mmol} /$ day $(O)$ and of 19 patients receiving placebo $(O)$ over 15 weeks.

${ }^{\star} \mathrm{p}<0.05,{ }^{\star \star} \mathrm{p}<0.01,{ }^{\star \star \star} \mathrm{p}<0.001$. were measured with flame photometry and serum and urinary creatinine concentrations with the picric acid colorimetric method.

Two sided $t$ tests for unpaired observations and two way analysis of variance were used to compare the effects of potassium and placebo treatment. Multiple linear regression was used to examine the relation of changes in blood pressure during treatment with potassium supplements to different variables. All data are given as means (SEM).

Based on the blood pressure variance during potassium and placebo treatment the study had a $90 \%$ chance of detecting a decrease of $8 / 7 \mathrm{~mm} \mathrm{Hg}$ in blood pressure at a significance level of $p=0 \cdot 05 .{ }^{19}$

\section{Results}

All patients completed the trial without suffering any adverse effects, and all seemed to comply with the treatment satisfactorily throughout the study.

The active treatment group and the placebo group were similar in all respects at the start of the study (table I); thus the effectiveness of potassium supplements could be evaluated by directly comparing the respective blood pressure measurements at various time points during treatment. As figure 1 shows, the mean blood pressure in the active treatment group decreased gradually and was significantly lower compared with that in the placebo group at virtually all time points. Table II shows the mean difference between the two groups at the end of the 15 weeks. The blood pressure of the group who received potassium was also significantly reduced compared with its baseline blood pressure value, as tested by a one way analysis of variance with Duncan's test for multiple comparisons $(p<0.001)$. Supine systolic blood pressure fell by at least $10 \mathrm{~mm} \mathrm{Hg}$ and diastolic blood pressure by at least $7 \mathrm{~mm} \mathrm{Hg}$ in 11 patients who received potassium (fig 2). A supine blood pressure of less than $140 / 90 \mathrm{~mm} \mathrm{Hg}$ was attained by 14 of 18 patients.

Heart rate did not change significantly (supine +3.4 and -1.7 beats $/ \mathrm{min}$; standing +0.5 and -0.3 beats $/ \mathrm{min}$ in groups treated with potassium and placebo, respectively); body weight decreased slightly in both groups $(-0.5$ and $-0.4 \mathrm{~kg}$, respectively).

There were no significant changes in plasma sodium concentration $(143(1) v 141(2) \mathrm{mmol} / \mathrm{l})$ and plasma potassium concentration $(4 \cdot 4(0 \cdot 1) v$ $4 \cdot 3(0 \cdot 1) \mathrm{mmol} / \mathrm{l})$ in patients who received potassium treatment. The mean 24 hour urinary potassium excretion, however, increased significantly in the group who received potassium supplements $(87$ (4) $v 57$ (4) mmol/24 h, $\mathrm{p}<0.005$ ), while the 24 hour urinary sodium excretion did not change $(189(10) v 183(10) \mathrm{mmol} / 24 \mathrm{~h})$.

In multivariate analysis no significant correlations were found between changes in blood pressure during treatment and several other variables-for example, age, baseline urinary potassium and sodium excretions, changes in urinary electrolyte concentrations, and changes in body weight. 
As figure 3 shows, the subgroup of 13 patients who underwent a further nine weeks of treatment with oral potassium supplements at half of the previous daily dosage ( $24 \mathrm{mmol} /$ day) showed a moderate increase in blood pressure during this period compared with the values achieved at the end of the full dose treatment $(+4 \cdot 5 /+2 \cdot 8 \mathrm{~mm} \mathrm{Hg}$ supine, $+1 \cdot 5 /+1 \cdot 0 \mathrm{~mm} \mathrm{Hg}$ standing; NS). Nevertheless, at the end of the nine weeks the average blood pressure of the patients who received potassium supplements was still significantly lower compared with that during the baseline period; it was also lower, but not significantly so, than that of the placebo group.

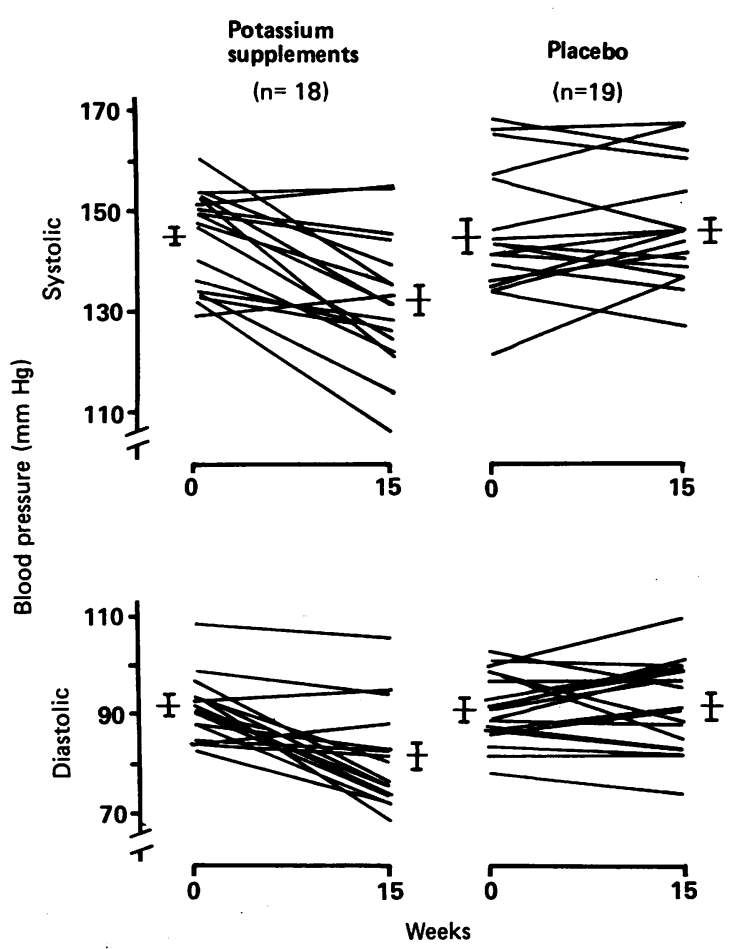

FIG 2-Individual changes in supine blood pressure between baseline and 15 weeks of treatment with potassium supplements or placebo. Bars represent SEM.

\section{Discussion}

Several trials of potassium supplements have been conducted in patients who have arterial hypertension, ${ }^{10} 1113.17$ but only a few of these have been controlled. Most of them were short term trials, and in some cases huge potassium supplements were prescribed. Not surprisingly, they have produced conflicting results.

The present study investigated the antihypertensive effect of chronic treatment with moderate oral potassium supplements and normal diet in patients who had mildly increased blood pressure. The study had a double blind randomised placebo controlled design. Randomisation was successful, as indicated by full comparability during the baseline period of the actively treated and placebo groups. Compliance with the potassium prescription was satisfactory in all cases, as confirmed by the significant increase in the mean 24 hour urinary potassium excretion in the actively treated group; the treatment was also well tolerated. The decrease in blood pressure observed in this group was biologically and statistically significant; most patients showed a meaningful blood pressure response, with an average decrease of $10 \%$ in the group compared with both the placebo group and baseline blood pressures. Systolic and diastolic pressure decreased to a similar extent in patients in both the supine and standing positions. The lack of a sizable decrease in blood pressure in the placebo group is probably explained by the opportunity given to the patients to become thoroughly familiar with the hospital staff and the study procedure during the two month run in period before the study and also by the fact that many of them had already received some pharmacological treatment in the past.
The subgroup of patients who underwent further treatment with only $24 \mathrm{mmol}$ potassium daily for nine weeks showed a small (not significant) increase in blood pressure compared with the values attained at the end of the full dose treatment period. Though the blood pressure of this subgroup remained significantly lower compared with its own baseline, it was no longer significantly lower compared with that of the placebo subgroup. As these subgroups of patients were selected from volunteers, however, caution must be exercised in extrapolating these data on low dose treatment to the whole study population.

Several different mechanisms have been proposed to account for the antihypertensive effect of a high potassium intake, including

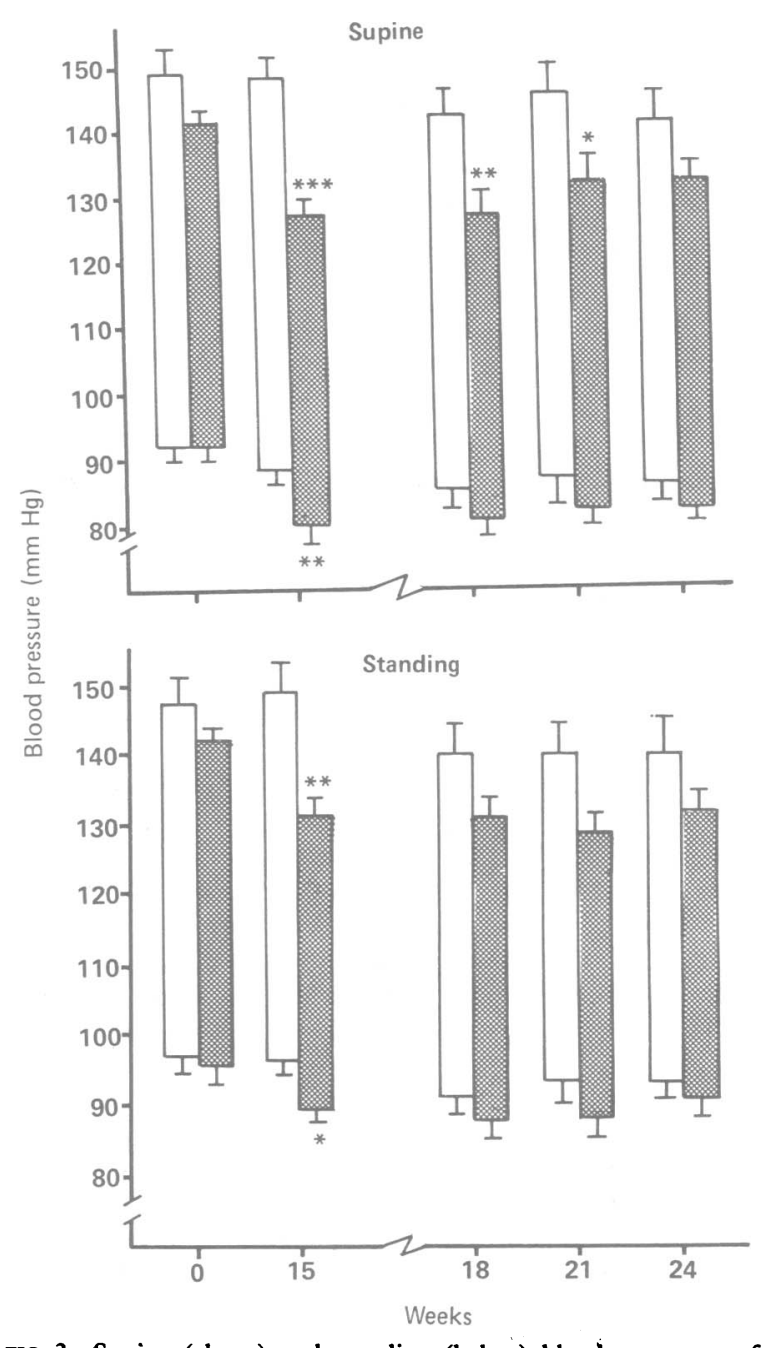

FIG 3-Supine (above) and standing (below) blood pressures of 13 patients receiving oral potassium supplements $(\mathrm{H})$ and of 10 patients receiving placebo $(\square)$ over 24 weeks. Potassium şupplements comprised $48 \mathrm{mmol}$ potassium daily from week 0 to week 15 and $24 \mathrm{mmol}$ potassium daily from week 15 to week 24 . Top edge of bar represents mean systolic pressure; bottom edge represents mean diastolic pressure. Bars represent SEM

${ }^{\star} \mathrm{p}<0.05,{ }^{\star \star} \mathrm{p}<0.01,{ }^{\star \star \star} \mathrm{p}<0.001$.

direct arteriolar dilatation, increased loss of water and sodium, suppression of secretion of renin and angiotensin, decreased adrenergic tone, and stimulation of the sodium-potassium pump activity. Interestingly, the magnitude of the decrease in blood pressure observed in patients receiving potassium supplements in different human studies seems to be related to the concomitant sodium intake: the higher the sodium intake the better the blood pressure response. ${ }^{10} 11$ is In addition, Smith et al did not observe any decrease in blood pressure in patients receiving $64 \mathrm{mmol}$ potassium supplements daily and a salt restricted diet $(70 \mathrm{mmol}$ daily $) .^{20}$ The findings of the present study agree with this view, as our patients had a fairly high mean sodium intake (about $200 \mathrm{mmol}$ daily). 
Moderate dietary supplements of potassium might be a valuable alternative to pharmacological methods for controlling blood pressure in patients who have less severe hypertension, particularly those who are not willing or able to restrict salt intake. Further studies should explore the possibility of achieving a substantial increase in potassium intake by acceptable, simple dietary modifications and confirm the long term safety and tolerability of this type of intervention.

\section{References}

1 Sasaki N. High blood pressure and the salt intake of the Japanese. $f p n$ Heart $\mathcal{f}$ 1962;3:313-6.

2 Yamori $Y$, Kihara $M$, Nara $Y$, et al. Hypertension and diet: multiple regression analysis in a Japanese farming community. Lancet 1981 ; i:204-6.

Langford HG. Dietary potassium and hypertension: epidemiologic data. Ann Intern Med 1983;98:770-2.

4 Louis WJ, Tabei R. Effects of sodium intake on inherited hypertension in the rat. Lancet 1971;ii:1283-6.

5 Dahl LK, Leitt G, Heine M. Influence of dietary potassium and sodium potassium molar ratios on the development of salt hypertension. $\mathcal{F}$ Exp Med 1972;136:318-20.

6 Dietz R, Shomig A, Rascher W, Strasser R, Ganten U, Kulber W. Partial replacement of sodium by potassium in the diet restores impaired noradrenaline inactivation and lowers blood pressure in stroke-prone spontaneously hypertensive rats. Clin Sci 1981;61(suppl):69-71.
7 Suzuki H, Kondo K, Saruta T. Effect of potassium chloride on the blood pressure in two kidney, one-clip Goldblatt hypertensire rats. Hypertension 1981;3:566-73.

8 Suzuki H, Kondo K, Saruta T. Inhibitory effect of potassium on blood pressure in DOCA salt hypertension in rats. Acta Endocrinol 1981;97:525-32.

9 Fujita T, Sato Y. Natriuretic and antihypertensive effects of potassium in DOCA-salt hypertension in rats. Kidney Int 1983;24:731-9.

10 limura $\mathrm{O}$, Kijima $\mathrm{T}$, Kikuchi $\mathrm{K}$, et al. Studies on the hypotensive effect of high potassium intake in patients with essential hypertension. Clin Sci 1981;61(suppl):77-80.

11 MacGregor GA, Smith SJ, Markandu ND, Banks RA, Sagnella GA. Moderate potassium supplementation in essential bypertension. Lancet 1982;ii:567-70.

12 Khaw KT, Thom S. Randomised double blind crossover trial of potassium on blood pressure in normal subjects. Lancet 1982;ii:1127-9.

13 Overlack A, Muller HM, Kolloch R, et al. Long-term antihypertensive effect of oral potassium in essential hypertension. 7 Hypertension 1983;1(suppl 2):165-7.

14 Richards AM, Nicholls MG, Espiner EA, et al. Blood pressure response to moderate sodium restriction and to potassium supplementation in mild essential hypertension. Lancet 1984; $757-61$.

15 Fujita T, Katsuyuki A. Hemodynamic and endocrine changes associated with potassium supplementation in sodium-loaded hypertensives. Hypertension 1984;6:184-92.

16 Zoccali C, Cumming AMM, Hutcheson MJ, Barnett P, Semple PF. Effect of potassium on sodium balance, renin, noradrenaline and arterial pressure. $f$ Hypertension 1985;3:67-72.

17 Matlou SM, Isles CG, Higgs A, et al. Potassium supplementation in blacks with mild to moderate essential hypertension. $\mathcal{F}$ Hypertension 1986;4:61-4.

18 Wright BM, Dore CF. A random zero sphygmomanometer. Lancet 1970; i:337-9.

19 Bulpitt CJ. Randomized controlled clinical trials. The Hague: Martinus Nijhoff, 1983:96-117.

20 Smith SJ, Markandu ND, Sagnella GA, MacGregor GA. Moderate potassium chloride supplementation in essential hypertension: is it additive to moderate sodium restriction? $\mathrm{Br} M e d$ f 1985;290:110-3.

(Accepred 9 March 1987)

\title{
Alcohol intemperance and sudden death
}

\author{
HANS LITHELL, HANS ÅBERG, INGEMAR SELINUS, HANS HEDSTRAND
}

\begin{abstract}
Ten years after a health screening examination was offered to 50 year old men 32 of the 2322 participants and 12 of the 454 nonparticipants had died of ischaemic heart disease. Of these, 26 and 11 respectively had suffered sudden death, for which necropsy was performed. Half of the men who had died suddenly had been registered for alcohol intemperance up to 1973, which was four times the prevalence of such registrations in the general population. Registration at both the Swedish Temperance Board and the Bureau of Social Services was associated with an odds ratio of 3.74 for sudden death as compared with not being registered at either. Logistic analysis including the classical risk factors for ischaemic heart disease together with registration for alcohol intemperance and at the Bureau of Social Services showed only the two types of registration and systolic blood pressure to be independent risk factors. On the other hand, there was no overrepresentation of subjects entered in the registers among those surviving a myocardial infarction. For non-fatal myocardial infarction blood pressure and serum triglyceride concentration were significant risk factors and serum cholesterol concentration, smoking, and body mass index probable risk factors; the two types of registration were not independent risk factors.
\end{abstract}

Alcohol intemperance is strongly associated with an increased risk of sudden death after myocardial infarction.

Department of Geriatrics, University of Uppsala, Box 12042, S-75012 Uppsala, Sweden

HANS LITHELL, MD, associate professor

INGEMAR SELINUS, MSC, statistician

Department of Family Medicine, University Hospital, S-75185 Uppsala, Sweden

HANS ÅBERG, MD, associate professor

Department of Medicine, Central Hospital, S-65185 Karlstad, Sweden

HANS HEDSTRAND, MD, associate professor and head of department

Correspondence and requests for reprints to: Dr Lithell.

\section{Introduction}

Sudden, unexpected death has been a matter of much concern with regard to its underlying causes. Boyd in his textbook of pathology, gave four main reasons for such deaths-namely, "cerebral haemorrhage, shock, coronary artery thrombosis and visitation from God." The causes of sudden death have probably changed with time. Cerebral haemorrhage, for example, was common before the 1950s but diminished rapidly when effective treatment for hypertension became available. ${ }^{2}$ Stroke as a cause of death was still declining during the late 1970 s. $^{2}$ Cerebral microembolism may possibly be fatal and explain some cases. ${ }^{3}$ Coronary artery thrombosis may be difficult to diagnose after a sudden death, as histochemical signs may not have developed. ${ }^{4}$ Coroners are not allowed to state "sudden death, cause unknown" but must specify the reason for death. Hence when evidence of other disease is lacking sudden death is usually ascribed to ischaemic heart disease, though severe narrowing of the coronary arteries may be absent. ${ }^{3}$

A history of alcohol abuse is more common in cases of sudden death than in people who survive a myocardial infarction. ${ }^{5}$ Furthermore, that cardiac arrhythmia may occur during or after an alcoholic binge ${ }^{6}$ suggests that alcohol may be a causative factor in sudden death. Few studies, however, have focused on whether alcohol consumption carries a risk independent of the conventional risk factors for ischaemic heart disease. We therefore present the findings with respect to sudden death in a population of some 2700 middle aged men who were followed up for almost 10 years. We report on the relative importance of the conventional risk factors for ischaemic heart disease, in particular for non-fatal myocardial infarction, and on registration at the Swedish Temperance Board as a risk factor for sudden death classified at necropsy as due to ischaemic heart disease.

\section{Subjects and methods}

Health screening was offered to 50 year old men in Uppsala during 1970-3 and $2322(84 \%)$ of the available population of 2776 men attended. Those found to have hypertension and hyperlipidaemia began treatment for their 